http://jurnalstttenggarong.ac.id/index.php/JTP

Sekolah Tinggi Teologi Tenggarong

p-ISSN 2722-8916, e-ISSN 2722-8908

Edisi: Volume 2, Nomor 1, Juni 2021

halaman: $42-55$

\title{
Mewujudkan Partisipasi Umat Dalam Liturgi Di Paroki Mbeling Dalam Semangat Sacrosantum Concilium
}

\author{
Mathias Jebaru Adon \\ Sekolah Tinggi Filsafat Teologi Widya Sasana Malang-Jawa Timur \\ Email:mathiasjebaruadon@gmail.com
}

\begin{abstract}
Abstrak:
Tulisan ini bertujuan mengurai langkah pastoral untuk mewujudkan partisipasi aktif umat dalam liturgi di Paroki St. Antonius Mbeling-Manggarai NTT sebagaimana yang tertuang dalam Sacrosantum Concilium Vatikan II. Di Paroki Mbeling kehidupan liturgi mendapat tantangan yang hebat. Umat yang hadir dalam perayaan liturgi bersifat pasif. Hal ini disebabkan karena pemahaman liturgi yang kurang memadai. Berdasarkan hal tersebut studi mengingatkan pelaku pastoral Paroki Mbeling untuk kembali ke hakikat liturgi sebagai puncak dan sumber hidup orang Kristiani. Caranya dengan mengembalikan liturgi sebagai perayaan doa. Sebab semangat doa yang baik membangkitkan dinamisme liturgi. Metode penelitian yang digunakan adalah keterlibatan langsung dengan dinamika hidup umat. Melalui keterlibatan ini ditemukan langkah pastoral yang sesuai dengan konteks persoalan umat. Hasil penelitian ini berupa saran-saran pastoral yang dapat meningkatkan keterlibatan umat dalam perayaan liturgi. Tesis dasarnya liturgi sebagai perayaan bersama maka dituntut partisipasi aktif umat.
\end{abstract}

Kata Kunci: Paroki Mbeling, Liturgi, Partisipasi Umat dan Sacrosantum Concilium.

\begin{abstract}
:
This paper aims to describe pastoral steps to realize active participation of the people in the liturgy in the Parish of St. Antonius Mbeling-Manggarai NTT as stated in Sacrosantum Concilium Vatican II. In Mbeling Parish, liturgical life was met with great challenges. The people who attend the liturgical celebration are passive. This is due to inadequate understanding of the liturgy. Based on this, the study reminds pastoral practitioners of Mbeling Parish to return to the essence of the liturgy as the pinnacle and source of Christian life. You do this by returning the liturgy as a prayer celebration. Because a good spirit of prayer evokes liturgical dynamism. The research method used is direct involvement with the dynamics of the life of the people. Through this involvement, pastoral steps are found that are in accordance with the context of the community's problems. The results of this research are in the form of pastoral suggestions that can increase the involvement of the people in liturgical celebrations.
\end{abstract}

Keywords: Mbeling Parish, Liturgy, Community Participation and Sacrosantum Concilium.

Article History

Submit: Revised:

Published:

May $20^{\text {th }}, 2021$

June $21^{\text {st }}, 2021$

June $30^{\text {th }}, 2021$

\section{Pendahuluan}

Paroki St. Antonius Padua Mbeling adalah salah satu paroki di keuskupan Ruteng. Paroki ini baru berumur 16 tahun. Letaknya di bagian timur Keuskupan Ruteng, di bawah naungan Kevikepan Borong, Kab. Manggarai Timur. Secara geografis Paroki St. Antonius 
Padua Mbeling adalah salah satu paroki yang cukup strategis karena letaknya di daerah pegunungan dan menjadi bagian dari ibu kota Kabupaten Manggarai Timur. Secara demografi umat Paroki Mbeling cukup majemuk baik dari segi budaya maupun agama. Hal ini disebabkan karena paroki Mbeling berada di pusat pemerintahan Kabupaten Manggarai Timur. Selama menjalani tahun pastoral selama 10 bulan pada tahun 2018/2019, tim pastoral Paroki Mbeling yang terdiri dari 2 orang imam dari Serikat Maria Montfortan (SMM) dan seorang frater SMM menemukan persoalan pastoral paroki berkaitan dengan keterlibatan aktif umat dalam liturgi. Kebayakan umat paroki menjadi pelaku yang pasif dalam kegiatan liturgi. Hal ini disebabkan karena pemahaman liturgi yang keliru yang menempatkan penerimaan komuni sebagai inti perayaan Ekaristi. Akibatnya tidak sedikit umat yang menghadiri perayaan liturgi semata-mata untuk menerima komuni.

Hal ini nampak dalam sikap dan keterlibatan aktif umat dalam liturgi. Pada hari Minggu sebagian besar umat datang terlambat dan bergegas masuk ke dalam Gereja ketika hendak menerima komuni. Padahal perayaan Ekaristi memiliki satu kesatuan tak terpisahkan sejak lagu pembuka hingga lagu penutup. Di dalamnya umat beriman memasuki misteri kehadiran Allah, terarah kepada Allah, berdialog dengan Allah, menyatakan kepercayaannya kepada Allah melalui aneka macam sarana: kata, benda dan gerak. Dengan kata lain perayaan Ekaristi menuntut keterlibatan penuh dan aktif dari umat beriman. Sebab tidak ada faedahnya sebuah perayaan Ekaristi yang telah dipersiapkan dengan sangat cermat dari sisi teks liturginya juga para petugasnya, tetapi umat beriman hadir terlambat atau selama perayaan Ekaristi umat sibuk dengan handphone-nya (Martasudjita, 2012). Penghayatan liturgi seperti ini sangat bertentangan dengan semangat Sacrosatum Concilium Vatikan II yang menyatakan liturgi khususnya sakramen Ekaristi adalah tindakan kehadiran Allah yang menebus manusia dan karya manusia yang memuliakan Allah. Dalam liturgi Allah datang kepada manusia, berdialog dengan manusia dan manusia menanggapi kehadiran Allah itu melalui nyanyian, doa dan syukur yang dilakukan secara bersama-sama (Hardawiryana, 1990).

Berdasarkan hal tersebut tulisan ini pertama-tama hendak menguraikan realitas sosial umat Paroki Mbeling sehingga ditemukan kegelisahan dan persoalan pastoral liturgi. Kedua, bagaimana umat Paroki Mbeling dapat berperan secara aktif dalam liturgi sehingga selaras dengan semangat Sacrosantum Concilium Konsili Vatikan II. Hasil penelitian ini kemudian dijadikan pedoman dalam menentukan langkah pastoral liturgi yang sesuai dengan realitas konkret umat Paroki Mbeling. Pada bagian akhir tulisan akan diberikan usulan-usulan pastoral yang dapat menjawab kegelisahan kehidupan liturgi umat Paroki Mbeling.

\section{Metode Penelitian}

Studi penelitian ini menggunakan metode penelitian kualitatif melalui observasi langsung. Penulis melaksanakan program pastoral di Paroki St. Antonius Padua Mbeling sejak 20 Agustus 2018 sampai 2 Juni 2019. Dalam penelitian itu penulis terlibat secara langsung dalam dinamika hidup umat Paroki St. Antonius Padua Mbeling. Bersama umat secara khusus 
para pemimpin umat dan pastor Paroki Mbeling, penulis merancang program pastoral bersama yang sesuai dengan kebutuhan umat paroki. Dalam penelitian itu penulis hadir sebagai petugas pastoral Gereja, yang melayani umat melalui pelayanan ibadat dan pembinaan iman umat. Dalam proses pelayanan penulis berkontak langsung dengan umat dan secara khusus dengan pemimpin-pemimpin stasi dan wilayah paroki. Dengan kata lain dalam penelitian ini penulis hadir bukan semata-mata sebagai peneliti yang sedang mengadakan observasi melainkan juga hadir sebagai pelayan jiwa-jiwa. Identitas penulis selama 10 bulan berada di paroki Mbeling dikenal sebagai Rohaniwan Katolik. Dengan identitas ini penulis dapat mengenal dan memahami dengan sungguh konteks persoalan liturgi umat Paroki Mbeling.

Selama mengadakan kegiatan pastoral, penulis mengadakan pengamatan mendalam dinamika hidup umat dengan membuat evaluasi setiap tiga bulan untuk melihat perkembangan dinamika hidup umat. Evaluasi ini dibuat bersama dengan petugas pastoral paroki yang lain seperti, pastor paroki dan dewan pastoral dari kalangan umat sendiri. Tujuannya untuk menemukan dan menentukan langkah pastoral yang tepat sesuai kebutuhan umat. Untuk mendukung dan mempertajam studi penulisan artikel ini penulis menggunakan sumber-sumber pustaka yang relevan dengan pokok permasalahan dalam artikel. Sumber-sumber pendukung tersebut berupa buku-buku, Jurnal Ilmiah dan Ajaran-ajaran Gereja Katolik yang berkaitan dengan pengembangan liturgi gereja katolik secara khusus teologi Ekaristi. Data-data ini didalami, dianalisis dan dirumuskan sehingga menjadi suatu tesis baru untuk dijadikan langkah pastoral yang sesuai dengan konteks persoalan umat dan menjawab kegelisahan pastoral liturgi Paroki St. Antonius Padua Mbeling.

\section{Hasil Dan Pembahasan}

\section{Liturgi Sebagai Sumber Dan Puncak Hidup Iman Menurut Sacrosantum Concilium}

Liturgi secara khusus perayaan Ekaristi adalah sumber dan puncak seluruh hidup kristiani. Hal ini menegaskan tugas dan panggilan Gereja untuk membawa umat beriman pada kesatuan yang tak terpisahkan antara hidupnya sehari-hari dengan liturgi yang dirayakan (Ardijanto, 2020). Umat beriman mesti sampai pada kesadaran bahwa panggilan dan perutusannya bersumber dan berpuncak pada perayaan liturgi. Karena itu pelaksanaan perayaan Ekaristi menuntut keterlibatan dan partisipasi aktif seluruh umat beriman. Sacrosantum Conciliusm (SC 50) menjelaskan hal ini dengan sangat baik bahwa, pelaku pastoral perlu menjelaskan setiap makna masing- masing bagian yang ada dalam liturgi secara khusus liturgi Ekaristi, serta hubungan antara satu bagian dengan bagian yang lain dalam kesatuannya dengan realitas pengalaman sehari-hari umat (Ristanto, 2020). Sebab tidak dapat dipungkiri dengan pengertian yang sungguh mengenai liturgi, umat beriman yang hadir dapat memasuki misteri yang dirayakan dan berkontak dengan Allah. Meski demikian perlu disadari bahwa dalam perayaan liturgi, ekspresi liturgis dari iman mesti tampak lebih segera dan langsung daripada ekspresi intelektual atau justifikasi iman mengenai argumen teologis atau ajaran dogmatis (Gunawan, 2018). Artinya, liturgi harus menjadi locus pengalaman akan Allah dan peristiwa 
liturgis membuat umat secara penuh menjadi tubuh Kristus di dunia. Tujuannya menumbuhkan kesadaran dalam diri umat untuk terlibat aktif sehingga perayaan Ekaristi membawa orang mengalami diri terarah kepada kepada Allah dan bertemu dengan Allah secara pribadi. Konsili memandang hal ini sebagai kewajiban Gereja untuk secara istimewa mengusahakan pembaruan dan pengembangan liturgi (SC, 1). Secara khusus hal ini dirumuskan dalam SC 37-38 bahwa, "Gereja dalam hal liturgi tidak boleh mewajibkan suatu keseragaman yang kaku, sebaliknya, ia harus memberi ruang kepada kemajemukan bentuk dan penyesuaian yang wajar dengan pelbagai kelompok, daerah, dan bangsa" (Ledot, 2002). Salah satu penyesuaian liturgi yang dilaksanakan sebagai bentuk kontekstualisasi liturgi di Paroki Mbeling dengan menjadikan torok (Bentuk doa permohonan orang Manggarai kepada Wujud Tertinggi) sebagai bagian dalam liturgi ritus perarakan persembahan pada perayaan ibadat Sabda Hari Raya Minggu Paskah tahun C/21 April 2019. Dalam ritus tersebut torok menjadi puncak perarakan persembahan. Di Keuskupan Ruteng langkah ini digalakkan sebagai model inkulturasi liturgi (Lanur, 2012). Melalui penyesuaian ini, Ekaristi dapat menjadi perayaan iman yang hidup, yang menyentuh dan membuat umat sungguh mengalami kebaikan Tuhan dan membawa pembaruan hidup (Martasudjita, 2012). Oleh sebab itu, segala bentuk karya kerasulan Gereja maupun kegiatan hidup harian jemaat bersumber dari daya kekuatan liturgi dan mengarah kepada liturgi. Dengan demikian liturgi tidak boleh berhenti hanya sebagai ritual rubrik atau devosi belaka. Tetapi, liturgi harus menyentuh realitas pergulatan hidup manusia sehari-hari. Sebab pada dasarnya, perayaan liturgi khususnya Ekaristi bukan sekedar sakramen tetapi misteri kehadiran Allah dalam hidup manusia.

Oleh sebab itu Gereja harus berusaha agar umat beriman yang mengikuti perayaan Ekaristi tidak hadir sebagai orang luar atau penonton yang bisu, melainkan terlibat secara penuh dalam doa dan memahami misteri itu dengan baik (SC, 48). Karena pada dasarnya hakikat liturgi adalah perjumpaan pribadi dengan Allah dalam doa, nyanyian, seperti yang tampak dalam hidup para rasul yang senantiasa "berkumpul bersama dalam doa dan memecahmecahkan roti (Kis 2:41-47)". Dengan cara ini umat beriman yang hadir dapat menanggapi perayaan liturgi dengan mudah, sehingga mereka terlibat secara penuh dan aktif dengan caranya yang khas sebagai jemaat (Prior, 2015). Hal ini berkaitan dengan disposisi batin umat yang membuat mereka tergerak untuk terlibat dan mengambil bagian dalam keseluruhan perayaan liturgi. Sebab disposisi batin yang baik dalam liturgi dapat dengan mudah membantu umat memasuki misteri Ekaristi. Persoalannya, bagaimana membangun disposisi batin yang baik bagi umat beriman agar keagungan misteri Ekaristi dirayakan dan dihidupi oleh umat.

Problem ini berkaitan dengan keterpesonaan atau kekaguman umat akan keagungan dan kekudusan Ekaristi (Saramae, 2014). Ketika umat memiliki keterpesonaan akan kekudusan Ekaristi itu, tentulah ia akan berusaha datang ke perayaan Ekaristi dengan penuh persiapan, rasa hormat dan khidmat sehingga dapat menimba kekuatan hidup dari Ekaristi. Oleh sebab itu, liturgi mesti dirancang semenarik mungkin sehingga membantu masuk dalam misteri yang dirayakan. Perayaan Ekaristi akan melelahkan apabila susunan doa dan pilihan nyanyiannya 
tidak menyapa situasi dan kondisi konkret hidup umat sehari-hari (Don Bosko Bakok, 2013). Sebaliknya, perayaan Ekaristi menjadi lebih menarik apabila ruang gedung gereja ditata dengan baik dan diperlengkapi dengan sound-system yang memadai, serta dekorasi panti imam atau altarnya dihias dengan bagus dan sesuai dengan masa liturgi serta susunan doa-doa yang menyapa pergulatan hidup umat(Tukan, 2017). Sacrosantum Concilium, no. 112 menyatakan hal ini dengan sangat jelas bahwa perayaan akan indah bila ada kesatuan antara hal-hal sekunder dalam liturgi seperti musik atau dekorasi dengan ungkapan-ungkapan doa yang mengena, karena dapat memupuk kesatuan hati dan memperkaya upacara suci sehingga perayaan menjadi meriah dan semarak. Lebih lanjut konsili menegaskan perayaan liturgi menjadi lebih agung, bila ibadat kepada Allah dirayakan dan dilayani oleh petugas- petugas liturgi yang terlatih dan bila umat ikut serta secara aktif (Hardawiryana, 1990).

Menghadapi tuntutan ini, Gereja perlu membaharui diri agar liturgi sungguh menjadi puncak hidup umat beriman sehingga menarik umat beriman memasuki misteri kehadiran Allah yang hidup. Maksudnya, dalam liturgi umat beriman dapat lebih mudah terarah kepada Allah, berdialog dengan Allah, menyatakan kepercayaannya kepada Allah melalui aneka macam sarana dan bentuk liturgi. Pembaruan ini dapat dilakukan dengan mengakomodasi bahasa setempat, dan simbol-simbol lokal yang sesuai, ataupun pemilihan musik yang sesuai dengan konteks budaya setempat dimana Gereja berada, sehingga umat bisa menghayati liturgi dengan segera dan kemudian mewujudkannya dalam kehidupan sehari-hari (Gunawan, 2018). Tetapi dalam penyesuaian ini Gereja tidak hanya memperhatikan konteks budaya tetapi juga konteks pergulatan hidup masyarakat yang riil seperti persoalan ekonomi, sosial dan politik. Misalnya Gereja dapat mengadakan ibadah dengan tema kebangsaan, dengan mengakomodasi simbolsimbol kebangsaan dan nyanyian-nyanyian wajib nasional dalam perayaan liturgi.

Singkat kata, umat beriman perlu dibina untuk semakin berpartisipasi secara aktif dan sadar serta terlibat penuh dalam misteri yang dirayakan. Keterlibatan ini bersumber dari Sakramen Baptis dimana umat beriman adalah "bangsa terpilih, imamat rajawi, bangsa yang kudus, umat kepunyaan Allah sendiri” (1Ptr. 2:9; lih.2:4-5). SC, 14 mengatakan hal ini dengan sangat jelas bahwa, bunda Gereja sangat menginginkan supaya semua orang beriman dibimbing ke arah keikutsertaan yang sepenuhnya, sadar dan aktif dalam perayaan-perayaan Liturgi (Hardawiryana, 1990). Sebab dengan ambil partisipasi secara aktif dalam liturgi umat beriman mengalami kehadiran misteri Kristus dan memperoleh penebusan Tuhan.

\section{Konteks Sosial Pastoral Paroki St. Antonius Padua, Mbeling}

Paroki St. Antonis Padua Mbeling adalah salah satu Paroki yang cukup besar dengan tipografi alam yang cukup menantang. Jumlah umat paroki St. Antonius Padua Mbeling pada tahun 2018 kurang lebih 8. 427 jiwa dengan jumlah 1. 595 KK (kepala keluarga). Ditinjau dari sudut pembagian usia, yang paling banyak adalah anak-anak, remaja dan kaum muda Katolik. Prosentase jumlah umat secara keseluruhan ialah Katolik 99, 8\%. Beberapa penduduk beragama Islam, mereka adalah pendatang dan hanya menetap di beberapa tempat di paroki 
Mbeling, seperti di stasi (district) Watu Mese dan stasi Purak. Meski demikian dalam kehidupan sehari-hari, umat menjalin relasi yang harmonis. Dari segi administrasi, Paroki Mbeling terdiri dari 5 wilayah, 8 stasi dengan jumlah 66 KBG. Dari 8 stasi ada 1 stasi yang ditempuh dengan berjalan kaki. 7 Stasi lain ditempuh dengan sepada motor tetapi dengan kondisi jalan yang sangat memprihatinkan karena medianya batu-batu.

Sebagian besar umat berprofesi sebagai petani. Ada yang bertani di sawah tetapi juga ada yang berladang. Dalam kehidupan berliturgi umat Paroki Mbeling sangat sederhana. Umumnya mereka tidak memikirkan bagaimana merayakan liturgi secara meriah. Bagi umat Paroki Mbeling yang paling penting dalam perayaan liturgi adalah menerima komuni. Dengan kata lain, liturgi hanya sebatas menyambut tubuh Kristus. Akibatnya dalam perayaan liturgi bagian konsekrasi (perubahan roti dan anggur) yang menjadi fokus perhatian umat. Pemahaman yang keliru ini kemudian mengakibatkan beberapa anak sekolah dasar (SD) memutuskan untuk tidak melanjutkan sekolah setelah menerima perayaan komuni pertama.

Secara umum, partisipasi dan keterlibatan umat dalam kehidupan liturgi kurang menunjukkan antusiasme yang baik. Peran aktif umat masih sangat kurang. Ketergantungan terhadap tim pastoral masih besar. Keikutsertaan dalam perayaan Ekaristi sebagai petugas liturgi hanya dijalankan oleh orang-orang tertentu dan umumnya guru-guru di sekolah dasar. Padahal di pusat paroki terdapat beberapa kelompok devosional umat seperti Legio Maria, KTM dan Kerahiman tetapi kelompok ini tidak berjalan sebagaimana mestinya. Perayaan liturgis dilihat hanya sebatas ritus dan seremoni, akibatnya setiap kali ada perayaan liturgi bersama tata gerak dan tata liturgis lain tidak disiapkan dengan baik karena umat tidak memiliki antusiasme. Selain itu, kesadaran akan kehadiran Allah dalam hidup sehari-hari masih sangat minim. Fenomena ini amat jelas terlihat dalam dinamika umat di stasi-stasi. Kesadaran umat untuk datang ke Gereja pada hari minggu masih sangat rendah, ada yang masih pergi ke kebun atau melewati hari Minggu sebagai hari libur semata. Kaum muda juga memperlihatkan kemunduran dalam semangat untuk mengikuti perayaan Ekaristi. Kebayakan kaum muda yang mengikuti perayaan Ekaristi pada hari Minggu hadir sebagai penonton dengan duduk di luar gereja dan masuk hanya untuk menerima komuni.

Fenomena lain yang juga terlihat adalah minimnya kesadaran dan penghormatan umat akan Gereja sebagai rumah Tuhan. Umat belum terbiasa menghormati Sakramen di dalam Tabernakel (tempat menyimpan Tubuh dan darah Kristus) baik ketika masuk ke gereja (dengan berlutut) maupun ketika pergi ke panti imam. Banyak anak SD yang bermain berlarian di dalam Gereja. Tim pastoral paroki juga menemukan bahwa umat kurang memiliki rasa hormat kepada Sakramen dan ketidakmampuan membedakan tempat yang sakral dan tempat biasa. Selain itu tidak jarang team pastoral menemukan umat lebih antusias untuk mengikuti upacara-upacara adat daripada kegiatan-kegiatan gereja. Misalnya di beberapa kampung sering terjadi upacara adat atau pesta adat diadakan pada hari Minggu sehingga banyak umat yang tidak hadir dalam ibadat sabda mingguan. Fenomena ketidakhadiran ini tampak juga misalnya saat perayaan komuni pertama. Kebayakan umat memilih sibuk mempersiapkan pesta daripada menghadiri 
perayaan Ekaristi. Terkesan umat lebih taat terhadap ritual adat daripada perayaan-perayaan liturgis Gereja.

Berdasarkan hal tersebut, tim pastoral Paroki Mbeling menyadari bahwa penghayatan iman umat belum dewasa. Penghayatan iman hanya sebatas pada ritus dan seremoni. Hubungan antara liturgi dan kehidupan sehari-hari masih kurang nampak. Pemahaman yang kurang ini menyebabkan partisipatif mereka dalam kehidupan liturgi juga sekedarnya. Liturgi terkesan hanya milik imam dan para guru di sekolah, sedangkan umat pada umumnya hanya menjadi penonton. Tidak sedikit umat yang takut dan enggan untuk terlibat dalam tugas-tugas yang berkaitan dengan liturgi. Sehingga tidak mengherankan jika ketergantungan mereka terhadap para petugas pastoral sangat tinggi. Ada banyak hal dalam kaitannya dengan liturgi praktis tidak diketahui umat, misalnya, penggunaan warna dalam liturgi, masih banyak umat belum mampu membedakan penggunaan warna tersebut. Di sisi lain, ada beberapa stasi yang menyerahkan tanggung jawab yang berkaitan dengan liturgi kepada tim pengajar di sekolah. Di samping itu beberapa stasi berkembang prinsip bahwa mereka akan menghadiri kegiatan liturgi di kapela/gereja apabila ibadat itu dipimpin oleh frater dan imam.

\section{Menumbuhkan Keterlibatan Aktif Umat Paroki St. Antonius Padua, Mbeling Dalam Liturgi Dalam Semangat Sacrosantum Cocilium}

Keprihatinan pastoral liturgi paroki St. Antonius Padua Mbeling tersebut berkaitan erat dengan persoalan mendasar dari pastoral liturgi yakni bagaimana merayakan liturgi yang benar, indah dan menarik sehingga liturgi sungguh menjadi puncak hidup beriman. Karena itu liturgi mesti kembali ke semangat dasarnya sebagaimana tertuang dalam Sacrosantum Cocilium No. 2 bahwa, liturgi adalah perayaan yang membantu kaum beriman untuk dengan mudah memasuki misteri Paskah Kristus. Dengan kata lain liturgi adalah perayaan doa (Camnahas, 2018). Dalam doa umat akan disatukan dan terlibat secara penuh. Melalui pendekatan ini umat akan tergerak untuk ikut ambil bagian dalam liturgi. Karena itu dalam liturgi, umat mesti mengalami kehadiran Allah sebagai mysterium tremendum, fascinosum et impenetrabile (dahsyat, mempesona dan tak terhampiri). Artinya, perayaan liturgi mesti menyentuh dimensi afektif yang lebih dalam dan mendukung kehidupan. Sehingga liturgi tidak terkesan hanya mengulangi suatu peristiwa di masa lalu melainkan mengantar umat ke masa sekarang dengan segala pergulatan konkret hidup mereka sehari-hari \{FormattingCitation\}. Hal ini sangat nampak dalam antusiasme umat paroki Mbeling dalam mengikuti berbagai bentuk devosi yang populer seperti doa rosario bersama, Novena dan devosi penyembahan sakramen Maha Kudus di Paroki yang dilaksanakan setiap hari jumat pekan pertama dalam bulan. Dalam kegiatan devosional ini umat dapat menjawab peristiwa dan pengalaman hidupnya secara spontan dan segera serta melibatkan dimensi emosional. Dengan kata lain, ibadah yang kering yang mereka temukan dalam perayaan Liturgi mendapat kesegarannya dalam devosi yang diungkapkan secara emosional dan spontan dan dijalankan dalam keseharian hidup umat. Dengan kata lain, 
antusiasme umat dalam berbagai bentuk kegiatan devosional menujukan kebutuhan besar umat akan bentuk ibadah yang menyentuh afeksi.

Karena itu, menjawab persoalan pastoral liturgi Paroki Mbeling beberapa hal dapat dikembangkan untuk mendukung dan membangkitkan semangat keterlibatan dan penghayatan liturgis umat seperti, pengembangan semangat kelompok-kelompok devosional yang ada seperti Legio Maria, KTM dan Kerahiman yang sudah terbentuk di paroki. Semangat marial yang menjadi ciri khas Legio Maria dapat menjaga dan merawat semangat devosional umat akan Bunda Maria yang tampak dalam antusiasme umat dalam doa Rosario bersama. Hal yang sama juga yang terjadi dengan KTM yang menawarkan peran penting roh kudus dalam dinamika hidup iman sehingga dapat menumbuhkan semangat devosional umat akan berbagai macam spiritualitas yang ditawarkan Gereja. Demikian juga dengan kelompok Kerahiman dapat membangkitkan semangat doa umat karena kelompok ini menawarkan semangat novena kepada Hati Kudus Yesus. Karena itu, kehadiran kelompok-kelompok ini akan memudahkan pastor paroki untuk membina umat agar terlibat secara aktif dalam kehidupan liturgi. Secara khusus menjadikan liturgi sebagai perayaan doa. Kehadiran kelompok ini dapat membantu pastor paroki untuk mendidik umat berkaitan dengan hal-hal praktis liturgi seperti warna yang selaras dengan tema perayaan berlangsung dan melatih lagu-lagu liturgis. Sebab tidak dapat dipungkiri semangat devosional kelompok-kelompok dapat mendidik umat untuk memiliki rasa hormat, kagum, cinta, tobat dan syukur kepada Allah (Verdino, 2017). Karena itu melalui devosi, liturgi mendapat kesegarannya dan menjadi sekolah iman yang mengarahkan perhatian umat kepada misteri inkarnasi, sengsara, wafat dan kebangkitan Kristus.

Singkat kata dengan mengembangkan semangat devosional secara tidak langsung mendidik dan mengajak umat untuk lebih serius dalam liturgi. Maka pengembangan kelompokkelompok devosional dalam paroki adalah langkah awal bagi pembinaan umat untuk terlibat secara penuh dalam liturgi. Respon umat paroki Mbeling terhadap kehadiran kelompokkelompok devosional ini cukup baik. Dari data yang ditemukan dalam arsip sekretariat paroki Mbeling minat umat terhadap kehadiran kelompok Legio Maria cukup baik. Hal ini dibuktikan dengan penambahan anggota baru legio Maria setiap tahun dan perubahan status kelompok Legio Maria dari presidium dan menjadi kuria. Kelompok Legio Maria juga tidak hanya berkembang di Pusat Paroki tetapi juga di 2 stasi yakni Stasi Perang dan Stasi Lumu keduanya menjadi bagian dari Legio Maria yang ada di Pusat Paroki. Hal yang sama juga terjadi dengan kelompok KTM yang mengalami peningkatan setiap tahunnya meski anggota KTM sebagian besar anggotanya adalah anak-anak sekolah dasar dan menengah pertama tetapi kehadiran mereka cukup memberikan sumbangsih yang besar dalam menumbuhkan iman umat. Sedangkan kelompok Kerahiman tidak mengalami penambahan anggota yang cukup signifikan seperti kelompok KTM dan Legio Maria tetapi anggota kelompok ini menyebar di hampir di 8 stasi Paroki Mbeling.

Dengan kata lain devosi yang subur di tengah umat akan meningkatkan partisipasi aktif umat dalam liturgi. Oleh sebab itu, melalui devosi perayaan liturgi menjadi efektif karena 
mengundang umat masuk dalam dimensi ruang dan waktu Allah yang menyelamatkan. Merasakan hubungan yang mesra dan mendalam bersama Tuhan. Oleh karena itu, setiap kali liturgi dapat menyentuh pengalaman terdalam umat, aspek yang berulang dari kegiatan perayaan liturgi tidak pernah membuat umat beriman bosan karena mereka mengalami dunia misteri (Don Bosko Bakok, 2013). Di sinilah peran liturgi sebagai doa, membantu umat bergerak melampaui saat sekarang ke dimensi yang menakjubkan ini, di mana orang-orang mengalami Tuhan dalam dalam hidupnya yang terdahulu. Inilah keterpesonaan kekudusan Ekaristi yang mesti dipelihara melalui hidup doa dan devosi yang teratur sebab sangat membantu umat beriman untuk menghayati misteri dengan tepat.

Hal ini diungkapkan oleh Paus Benediktus sebagai ars celebrandi. Ars celebrandi adalah seni merayakan liturgi. Bagi Paus Benediktus XVI, ars celebrandi dapat memajukan suatu kepekaan terhadap yang kudus lewat penggunaan tanda-tanda lahiriah yang membantu umat mengembangkan kepekaan liturgi (Martasudjita, 2012). Ars Celebrandi mengandaikan keterlibatan seluruh umat, bukan hanya pekerjaan para liturgi profesional atau para imam. Sebab jika gaya liturgi menjadi milik eksklusif para ahli liturgi, maka liturgi akan kehilangan hati dan roh. Dengan kata lain, perhatian yang berlebihan pada ketepatan liturgi atau berjalan menurut buku akan mengarahkan liturgi pada ossifikasi ritual. Gaya liturgi semacam itu membuat umat sulit memahami dan memasuki misteri yang dirayakan yang justru dibutuhkan untuk menyambut dan merasakan misteri Allah yang menebus. Karena itu Sacrosantum Concilium No. 14 menegaskan bahwa, dalam pembaharuan dan pengembangan liturgi suci keikutsertaan segenap umat secara penuh dan aktif perlu beroleh perhatian yang terbesar. Sebab kaum beriman merupakan sumber utama yang tidak tergantikan, untuk menimba semangat kristiani yang sejati (Hardawiryana, 1990). Maka dari itu dalam seluruh kegiatan pastoral Gereja, para gembala jiwa harus mengusahakan dengan rajin pendidikan dan pendidikan liturgi untuk umat.

Berkaitan dengan konteks sosial pastoral liturgi Paroki Mbeling berikut ini diberikan langkah praktis untuk mewujudkan liturgi yang sesuai dengan semangat Sacrosantum Concilium (SC):

\section{Pelatihan Misdinar (Putra Altar)}

Pelatihan misdinar adalah langkah awal yang konkret yang langsung menjawab persoalan pastoral berkaitan dengan kurangnya rasa hormat anak-anak sekolah dasar yang sering bermain di dalam Gereja. Dengan mendidik mereka menjadi putra altar mereka akan belajar menghormati tabernakel dan panti imam sebagai tempat yang sakral dalam gereja. Selain itu pelatihan misdinar adalah persiapan bagi umat masa depan yang sudah dilibatkan sejak usia dini. Pendidikan sejak usia dini dapat menumbuhkan kesadaran yang mendalam bagi partisipasi liturgi ketika dewasa. Mengingat medan pastoral stasi-stasi Paroki Mbeling yang cukup menantang, pendidikan itu dapat diwujudkan dengan pelatihan setiap kali ada kunjungan imam ke stasi. Oleh karena itu, tim pastoral Paroki Mbeling membuat kesepakatan dengan 
pembina misdinar agar mengadakan latihan misdinar pada setiap hari kamis pukul 16.00-17.00 di pusat Paroki. Tim pastoral memulainya di pusat paroki dan melibatkan tenaga awam yang akan menjadi pembina selanjutnya. Melalui keterlibatan umat dalam pembinaan akan memudahkan tenaga pastoral selanjutnya serta dapat menumbuhkan keterlibatan awam dalam merancang liturgi yang baik dan benar. Sementara untuk stasi-stasi pelatihannya diadakan setiap ada kunjungan. Dalam proses pelatihan tim pastoral berusaha melibatkan sepenuhnya peran pembina misdinar yang sudah pernah ada di stasi-stasi.

\section{Pelatihan Lektor/tris dan Pemazmur}

Sebagaimana yang terungkap dalam Sacrosantum Concilium keikutsertaan aktif dalam membaca dan menyanyikan lagu bersama-sama akan lebih membantu umat memasuki misteri paskah Kristus. Lagu yang dinyanyikan dengan persiapan yang baik dan matang akan semakin membatu umat segera memasuki misteri iman dan semakin terarah kepada Kristus. Kekhidmatan dalam perayaan ekaristi juga sangat ditentukan oleh lektor dan lektris serta pemazmur (Don Bosko Bakok, 2013). Sebab tidak dapat dibayangkan jika lektor atau lektris tidak dapat membaca dengan baik saat perayaan berlangsung, juga jika mazmur tidak dinyanyikan dengan baik, perayaan ekaristi akan menjadi sandiwara. Oleh karena itu petugas pastoral menyempatkan diri untuk memberikan pelatihan di pusat paroki pada hari sabtu dan di stasi ketika memimpin upacara sabda pada hari minggu, baik sebelum maupun sesudah perayaan berlangsung. Untuk memudahkan proses pelatihan tim pastoral melibatkan kaum awam yang berpendidikan dan pelatih koor untuk melatih mazmur. Dengan keterlibatan awam yang kompoten ini diharapkan mereka menjadi jembatan yang menghubungkan petugas pastoral dengan peserta latihan serta memudahkan regenerasi. Selain itu, keterlibatan kaum awam ini dapat menimalisir rasa enggan para peserta dengan petugas pastoral.

\section{Pelatihan Musik liturgi}

Berdasarkan statistik Paroki Mbeling bahwa sebagian besar umat Paroki Mbeling adalah orang muda maka kehadiran musik yang baik dalam liturgi semakin membantu umat terhubung dengan misteri Kristus yang menyelamatkan. Musik yang indah akan menggerakkan dan memberi semangat dan warna yang baru secara khusus bagi kaum muda. Antusiasme dan dinamisme hidup liturgi umat tidak terlepas dari penyajian musik yang baik dalam liturgi. Melalui musik orang muda disambut dan diterima dalam perayaan liturgi karena dirayakan sesuai dengan semangat dan jiwa mereka (Hermawan, 2017). Musik juga dapat membantu umat untuk membuka hati pada sentuhan kasih Allah yang menyapa umat-Nya. Dalam proses pelatihanya tim melibatkan beberapa awam yang kompeten untuk merancang kegiatan pelatihan lagu-lagu yang terdapat di Madah bakti dan Puji Syukur yang sesuai. Berdasarkan keprihatinan tersebut tim pastoral Paroki Mbeling membuat jadwal pelatihan dua kali dalam seminggu yakni pada hari Rabu dan Sabtu pkl. 16.00-17.00 di Gedung Gereja Paroki St. 
Antonius Padua. Tujuannya untuk menambah perbendaharaan lagu-lagu pada saat perayaan ekaristi harian sekaligus menambah perbendaharaan lagu-lagu umat.

\section{Katekese Liturgi}

Sebagaimana telah diungkapkan di atas liturgi semakin dihayati jika umat memahami dengan sungguh misteri yang dirayakan. Kurangnya pemahaman yang baik mengenai liturgi seringkali membuat umat memahami liturgi hanya sebatas ritus dan seremoni belaka (Ristanto, 2020). Karena itu peran katekese tentang liturgi dapat membantu umat dewasa untuk terlibat dan mengambil bagian secara penuh dalam liturgi. Maka peran katekese memainkan peran yang sentral bagi penghayatan liturgi yang baik. Program katekese liturgi di Paroki mbeling dilaksanakan sekali dalam setahun dan tidak dilakukan di semua stasi. Hal ini disebabkan karena keterbatasan waktu dan tenaga mengingat wilayah Paroki Mbeling yang cukup luas. Waktu pelaksanaannya dilaksanakan selama masa prapaskah. Tahun 2018 katekese liturgi di laksanakan di stasi perang dan Purak. Kedua stasi ini dipilih karena partisipasi dan keterlibatan umat dalam perayaan liturgi masih kurang.

\section{Pelaksanaan Perayaan liturgi Inkulturasi}

Sebagai langkah praktis perwujudan liturgi sesuai semangat Sacrosantum Concilium dirancang model inkulturasi liturgi. Caranya dengan memasukan torok dalam perayaan Ibadat Sabda pada hari Raya Paskah pada tahun C/21 April 2019. Bagi orang Manggarai torok adalah ungkapan yang disusun dalam syair-syair indah untuk menyatakan maksud-maksud tertentu dan ditujukan kepada Wujud Tertinggi ataupun kepada leluhur. Torok selalu disampaikan dalam konteks upacara adat komunal seperti; "Penti" (upacara syukur panen), upacara kehamilan (lamba wakas) dan kelahiran (cear cumpe), upacara perkawinan, upacara kematian, upacara adat "lingko" (kebun komunal). Melalui upacara-upacara ini doa-doa didaraskan kepada Wujud Tertinggi. Torok pula kerap disebut sebagai doa asli orang Manggarai dan disampaikan dalam suasana sakral serta penuturnya merupakan representasi dari peserta yang hadir dalam upacara tersebut.

Berdasarkan tujuan dan maksud torok di atas sangat tepat jika torok dimasukkan dalam liturgi sebagai bagian dari persembahan diri umat. Sebagaimana yang diungkapkan dalam Sacrosantum Concilium liturgi mesti menyentuh realitas keseharian hidup umat dan merupakan ungkapan iman umat yang real. Oleh karena itu dirancang liturgi inkulturatif dengan memasukan torok ketika umat mengantar persembahan ke altar untuk disatukan dengan kurban Kristus. Artinya umat mempersembahkan seluruh dirinya, baik apa yang dimiliki (rezeki), harapan, cita-cita dan secara khusus dirinya yang diungkapkan dalam torok. Karena itu sangatlah tepat jika torok yang berisi untaian kata-kata pujian dan permohonan dimasukkan dalam liturgi sebagai bentuk persembahan dan partisipasi umat dengan persembahan diri Kristus di altar. Berikut ini susunan tata perayaan Ibadat Hari Raya Paskah dimana torok dimasukan sebagai bagian dalam perayaan liturgi. 


\begin{tabular}{|c|c|c|c|}
\hline Ritus Pembuka & Liturgi Sabda & Upacara Doa & Penutup \\
\hline $\begin{array}{l}\text { 1. Komentator } \\
\text { 2. Lagu Pembuka } \\
\text { 3. Tanda Salib dan } \\
\text { Salam } \\
\text { 4. Kata Pembuka } \\
\text { 5. Pernyataan } \\
\text { Tobat } \\
\text { 6. Tuhan } \\
\text { Kasihanilah } \\
\text { Kami } \\
\text { 7. Madah } \\
\text { Kemuliaan } \\
\text { 8. Doa Pembuka }\end{array}$ & $\begin{array}{l}\text { 9. Komentator } \\
\text { 10. Bacaan I: Kis } \\
\text { 10:34a.37-43 } \\
\text { 11. Mazmur } \\
\text { Tanggapa } \\
\text { 12. Bacaan II: Kol } \\
\text { 3:1-4 } \\
\text { 13. Madah Paskah } \\
\text { (Sekuensia) dan } \\
\text { Alleluya } \\
\text { 14. Bacaan Injil: } \\
\text { Yoh 20:1-9 } \\
\text { 15. Homili } \\
\text { 16. Aku Percaya } \\
\text { 17. Doa Umat }\end{array}$ & $\begin{array}{l}\text { 18. Komentator } \\
\text { 19. Arakan } \\
\text { Persembahan } \\
\text { dan “Torok” } \\
\text { 20. Lagu } \\
\text { Persembahan } \\
\text { 21. Doa Syukur } \\
\text { 22. Kudus } \\
\text { 23. Kenangan akan } \\
\text { Kristus } \\
\text { 24. Bersatu Dalam } \\
\text { Roh Kudu } \\
\text { 25. Bapa Kami } \\
\text { 26. Komuni } \\
\text { 27. Lagu-Lagu } \\
\text { Komuni } \\
\text { 28. Doa Sesudah } \\
\text { Komuni }\end{array}$ & $\begin{array}{l}\text { 29. Pengumuman } \\
\text { 30. Pengutusan } \\
\text { 31. Lagu Penutup }\end{array}$ \\
\hline
\end{tabular}

Tabel 1. Tata Perayaan Ibadat Sabda Hari Raya Paskah (Yesus Bangkit dari Alam Maut)

\section{Kesimpulan}

Paroki St. Antonius Padua Mbeling Flores-NTT adalah salah satu paroki di Keuskupan Ruteng yang mengalami tantangan yang hebat berkaitan dengan pastoral liturgi. Kehidupan liturgi seringkali dipisahkan dengan kehidupan konkret umat. Hal ini tampak dalam keterlibatan umat dalam kehidupan liturgi. Liturgi seringkali menjadi urusan imam yang memimpin perayaan sedangkan umat hanya menjadi penonton. Hal ini disebabkan karena pemahaman umat yang masih terbatas mengenai liturgi sebagai perayaan bersama. Selain itu pemahaman yang keliru mengenai liturgi sebagai perayaan seremonial menjadikan umat tidak terlibat secara penuh dalam keseluruhan liturgi. Padahal hakikat liturgi adalah perayaan bersama dimana umat diantar masuk dalam perjumpaan pribadi dengan misteri paskah Kristus melalui aneka gerak, kata dan doa yang di tata dalam liturgi. Karena itu liturgi mengandaikan keterlibatan penuh umat dalam keseluruhan perayaan. Liturgi pada dasarnya memiliki satu kesatuan yang tak terpisah sejak lagu pembuka hingga lagu penutup sebab Allah menyapa dan berkomunikasi dengan manusia melalui seluruh dimensi dan bagian-bagian liturgi dan umat menanggapi kehadiran Allah tersebut dengan doa, lagu dan ucapan syukur.

Berhadapan dengan konteks situasi pastoral Paroki St. Antonius Padua, Mbeling yang cukup menantang liturgi mesti kembali ke semangat Sacrosantum Conclium bahwa liturgi adalah sebuah perayaan doa. Karena itu diperlukan langkah konkret yang tepat untuk dapat 
membantu dan menggerakkan umat agar terlibat secara aktif. Hal ini dapat dimulai dengan mengembangkan kelompok-kelompok devosional yang ada di paroki. Sebab tidak dapat dipungkiri kehadiran kelompok tersebut dapat mendidik umat untuk terlibat dalam liturgi. Di samping itu dikembangkan secara terus-menerus program pastoral paroki yang dimulai dari pembinaan anak usia dini hingga katekese liturgi untuk umat dewasa. Dengan langkah pastoral ini, keterlibatan dan partisipasi aktif umat akan semakin meningkat dan kehidupan iman umat akan bersumber dan berpuncak dalam liturgi.

\section{Daftar Rujukan}

Ardijanto, D. B. K. (2020). Perayaan Ekaristi Sebagai Sumber Dan Puncak Seluruh Hidup Kristiani. JPAK: Jurnal Pendidikan Agama Katolik, 20(1), 88-100. https://doi.org/10.34150/jpak.v20i1.255

Camnahas, A. (2018). Himpunan Doa Pelita Hati Dalam Sorotan Dokumen Gereja Tentang Liturgi Dan Devosi. Jurnal Ledalero, 29-50.

Don Bosko Bakok, Y. (2013). Musik Liturgi Inkulturatif di Gereja Ganjuran Yogyakarta. Resital: Jurnal Seni Pertunjukan, 14(1). https://doi.org/10.24821/resital.v14i1.392

Gunawan, H. A. (2018). Liturgi Sebagai Ruang Transformasi: Sebuah Tawaran Misional untuk Pembaruan Liturgi. Indonesian Journal of Theology, 1(July), 1-26.

Hardawiryana, R. (Ed.). (1990). Sacrosantum Concilium; Konstitusi Tentang Liturgi. In Dokumen Konsili Vatikan II (Seri Dokum). Jakarta: Depertemen Dokumentasi Dan Penerangan Konferensi Waligereja Indonesia.

Hermawan, A. J. (2017). Partisipasi Kaum Muda Dalam Perayaan Ekaristi. 06(November).

Lanur, A. (2012). Pandangan Hidup Orang Manggarai. In M. Chen and C. Suwendi (Eds.), Iman, Budaya dan Pergumulan Sosial (Refleksi Yubilium 100 Tahun Gereja Katolik Manggarai). Jakarta: Obor.

Ledot, I. (2002). SPIRIT SACROSANCTUM CONCILIUM Mendorong Sebuah Liturgi Yang Hidup, Kontekstual, Inkulturatif. Jurnal Ledalero, 1-12.

Martasudjita, E. P. D. (2012). TINJAUAN PASTORAL LITURGIS. Diskursus: Jurnal Filsafat Dan Teologi Sekolah Tinggi Filsaafat Driyakarya, 11(April), 101-122.

Prior, J. M. (2015). Liturgi: Sumber Kehidupan, Daya Iman bagi Kaum Pejuang. Setelah Setengah Abad: Ke Mana Kita Melangkah? Yogyakarta: Kanisius.

Ristanto, D. A. (2020). Dimensi Sosial Ekaristi Yohanes Paulus II dan Benediktus XVI. Jurnal Teologi, 9(2), 119-142. https://doi.org/10.24071/jt.v9i02.2671

Saramae, P. B. (2014). Konstitusi Liturgi Konsili Vatikan II : Prasejarah, Sejarah dan Naskahnya. Jurnal Orientasi Baru, 23(1), 31-56.

Tibo, P. (2018). Praktik Hidup Doa Dalam Keluarga Sebagai Gereja Rumah Tangga. Jurnal $\begin{array}{llll}\text { Jumpa, } & \text { VI(62), } & \text { 69-92. } & \text { Retrieved }\end{array}$ https://ojs.stkyakobus.ac.id/index.php/JUMPA/article/download/50/52

Tukan, A. I. N. (2017). Pengalaman Umat Dalam Devosi Sakramen Mahakudus Dan 
Merayakan Ekaristi Kudus. PASTORALIA Jurnal Penelitian Sekolah Tinggi Pastoral Kak, 53(9), 1689-1699.

Verdino, T. (2017). Indonesian Journal of Theology 5/2. Indonesian Journal of Theology, 2(5), $147-177$. 